\title{
Pet husbandry and infection control practices related to zoonotic disease risks in Ontario, Canada
}

Jason W Stull ${ }^{1,2,4^{*}}$, Andrew S Peregrine ${ }^{1,2}$, Jan M Sargeant ${ }^{2,3}$ and J Scott Weese ${ }^{1,2}$

\begin{abstract}
Background: Many human infections are transmitted through contact with animals (zoonoses), including household pets. Despite this concern, there is limited knowledge of the public's pet husbandry and infection control practices. The objective of this study was to characterize zoonotic disease related-husbandry and infection preventive practices in pet-owning households in Ontario, Canada.

Methods: A self-administered questionnaire was distributed to individuals at two multi-physician clinics in Waterloo, Ontario, Canada during 2010. One adult from each household was invited to participate in the study.

Results: Four hundred one pet-owners completed the questionnaire. Households reported ownership of dogs $(68 \%)$, cats (48\%), fish (13\%), exotic mammals (7\%), such as hamsters, and reptiles and birds (each 6\%). Across all species, individuals at higher risk of infections (i.e. $<5 \mathrm{yrs}, \geq 65 \mathrm{yrs}$, immunocompromised) were often (46-57\%) present in households. Children < 16 yrs of age had close pet contact, as households reported dogs (13\%) and cats (30\%) usually slept in a child's bed and dogs often licked a child's face (24\%). Household husbandry practices that increase zoonotic disease risk were frequently identified; some fed high-risk foods (i.e. raw eggs, raw meat, or raw animal product treats) to their dogs (28\%) or cats (3\%); $14 \%$ of reptile-owning households allowed the pet to roam through the kitchen or washed it in the kitchen sink. Reported hand washing by children was high for all species (> 76\% washed hands sometimes or greater after touching the pet, its feces, or housing), although fewer reported children always washed their hands (3-57\%; by species). With a few exceptions, practices were not associated with the presence of higher risk members in the household or recall of having previously received zoonotic disease education.
\end{abstract}

Conclusions: The results suggest there is a need for education on zoonotic disease prevention practices for pet-owning households with individuals at higher risk of infection and those with high-risk species (e.g., reptiles). Further research is needed to determine the role of education in altering higher risk pet practices.

Keywords: Zoonoses, Pet, Education, Infection, Husbandry, Canada

\section{Background}

Pet ownership is common, with the majority of households in many developed countries owning pets [1-8]. A recent study estimated that $56 \%$ of Canadian homes have at least one dog or cat, with a minority owning fish (12\%), birds (5\%), rabbits or hamsters (each $2 \%$ ), lizards, guinea pigs, snakes, frogs, turtles, ferrets, or gerbils (each 1\%) [6]. Pet ownership has been shown to have mental and physical

\footnotetext{
* Correspondence: Jason.Stull@cvm.osu.edu

'Department of Pathobiology, Ontario Veterinary College, University

of Guelph, Guelph, Ontario N1G2W1, Canada

${ }^{2}$ Centre for Public Health and Zoonoses, University of Guelph, Guelph,

Ontario N1G2W1, Canada

Full list of author information is available at the end of the article
}

benefits [9], particularly among children, the elderly and immunocompromised individuals [10-16]. However, despite these benefits, there are also potential health hazards associated with pet ownership and contact.

A recent estimate suggests that $14 \%$ of all human illness caused by seven common enteric pathogen groups (i.e., Campylobacter spp, Cryptosporidium spp, Shiga toxin-producing Escherichia coli (STEC) O157, STEC non-O157, Listeria monocytogenes, nontyphoidal Salmonella spp., and Yersinia enterocolitica) are attributable to animal contact [17]. Although the proportion of human disease for which pets are specifically responsible is largely unknown, greater than 70 pathogens of companion

\section{Biomed Central}

(c) 2013 Stull et al.; licensee BioMed Central Ltd. This is an Open Access article distributed under the terms of the Creative Commons Attribution License (http://creativecommons.org/licenses/by/2.0), which permits unrestricted use, distribution, and reproduction in any medium, provided the original work is properly cited. 
animals are known to be transmissible to people [18] and pet contact has been clearly established as a risk factor for illness caused by various pathogens, including Campylobacter [19,20], Salmonella [21], Pasteurella multocida [22] and Capnocytophaga canimorsus [23]. For some pet species, their role in human disease has been more clearly identified; reptiles and amphibians are estimated to be responsible for $6 \%$ of all sporadic Salmonella infections (11\% among persons less than 21 yrs old) [24]. The emergence and dissemination of multidrug-resistant bacteria in both humans and companion animals has created additional concerns [25,26].

People can acquire pet-associated zoonotic organisms through the skin and mucous membranes (via animal bites, scratches, or direct or indirect contact with animal saliva, urine and other body fluids or secretions), ingestion of animal fecal material, inhalation of infectious aerosols or droplets, and through arthropods or other invertebrate vectors [27]. Although any exposed person can become infected with a zoonotic pathogen, risks are particularly high for those with a compromised or incompletely developed immune system, such as the young $(<5 \mathrm{yrs})$, elderly ( $\geq 65$ yrs), pregnant and those with immune function-reducing conditions or treatments (e.g., diabetes, cancer, infection with human immunodeficiency virus (HIV), chemotherapy) [27,28].

Although incompletely understood, there are many factors that are involved in the occurrence of a zoonotic infection from a pet. Several of these factors likely have important roles in determining if an individual becomes infected, becomes symptomatic once infected, and the degree of illness that occurs. These include: 1) level and dose of exposure to the pathogen, 2) ability of the individual to suppress infection, with immunocompromised and extremes of age less able to successfully respond immunologically to pathogens, and 3) preventative veterinary care, husbandry and infection control practices that remove or reduce the level of the pathogen present and risk of transmission [27]. Existing recommendations stress that those at greatest risk for infectious disease should take the greatest precautions when interacting with pets, and be the most diligent in following infection prevention practices [29-35].

Despite the risk for pet-associated disease in people and role that appropriate infection control and husbandry practices may play in reducing disease risk, the area of household pet husbandry and infection practices has not been thoroughly investigated. The studies that have examined these topics, have noted the frequency of close contact between pets and people (e.g., licking of hands and sleeping in household member beds [36,37]), general pet ownership patterns by individuals at higher risk of disease [15,38-43], and general husbandry and infection control practices within pet-owning households (e.g., frequency of preventive veterinary care $[40,44]$, and occurrence of hand hygiene [36,37] and husbandry practices $[36,45])$. However, previous studies have not analyzed the associations between these factors, which would allow for a better understanding of how the factors may change with differing household disease risks or with prior receipt of zoonotic disease education. The objective of this study was therefore to characterize pet husbandry and infection control practices that relate to zoonotic disease risks in pet-owning households in Ontario, Canada. Additionally, the study aimed to integrate household demographics, including human disease risk status (i.e., extremes of age, immunocompromised) and prior receipt of zoonotic disease education to determine if these factors influenced household practices.

\section{Methods}

\section{Study location and selection of study sites}

The site chosen for this study was the region of Waterloo, located in southern Ontario, Canada. The Waterloo Region is composed of three urban and four rural municipalities. This region was selected as it includes both rural and urban settings and its population has similar demographics to the Province of Ontario and Canada as a whole [46]. As of 2006, this region had a population of approximately 478,000 people in 178,000 private households. The median age was 36.4 yrs, with $81 \%$ of the population greater than 14 yrs. Median household annual income was $\$ 65,000$ CAD [46]. These statistics are similar to those for the Province of Ontario and all of Canada, with the exception of a higher household median annual income $(\$ 60,000$ for Ontario, $\$ 54,000$ for Canada) [46].

Medical clinic and participant enrolment was part of a previously reported study that addressed knowledge and attitudes related to pet contact and associated zoonoses. Detailed enrolment methods and inclusion criteria are available elsewhere [47]. In brief, a convenience sample of multi-doctor general practice physician offices located within the Waterloo region was approached to participate in the study. Two practices agreed to participate (clinic A in Kitchener, Ontario and clinic B in Cambridge, Ontario).

\section{Data collection}

During October and November, 2010, adults present in the waiting areas of the participating clinics were individually approached and invited to take part in the study. Individuals were eligible to participate if they were at least 18 yrs of age, able to read and speak English, and no one from their household had previously taken part in the study. When more than one eligible adult for a given household was present in the waiting area, a single household volunteer was requested. Participants were asked to complete an anonymous, confidential, self-administered written general questionnaire. Individuals who currently 
had pets in their household were also given a selfadministered written 5-minute supplemental pet-specific questionnaire (Additional file 1). Household pets were defined as those that were indoor only, outdoor only, and those that spent time both indoor and outdoor. No incentives were offered for participating in the study.

The 7-page supplemental pet-specific questionnaire for this study was developed with guidance from epidemiologists, veterinarians, physicians and zoonotic disease experts. The questionnaire was pre-tested on six members of the public with varying zoonotic disease backgrounds, and revised accordingly. The final questionnaire utilized closed-ended questions, primarily Yes/No or multiple choice (using an ordinal scale). It gathered household-level data on the number and species of pets, pet husbandry and preventive medicine practices, involvement of children less than 16 yrs of age in select husbandry and pet-contact practices, childrens' utilization of infection control practices, and the household's and childrens' emotional attachment to pets. Given the complexity of capturing and assessing flea and endoparasite prevention programs for each household pet, respondents were asked if all household dogs/cats were on intestinal parasite and flea prevention programs, without further defining, verifying or assessing specific components of the programs. Individual supplemental questionnaires were linked by respondent to the general questionnaire [47], allowing select variables collected through the general questionnaire to be utilized for additional analysis in this study. The study was approved by the University of Guelph's Research Ethics Board.

\section{Data analysis}

Data were entered into an Access database (Microsoft Corp., Redmond, WA, USA) and analyzed using Intercooled Stata version 10.1 (Stata Corp., College Station, TX, USA). Descriptive statistics were computed for all variables. Blank and "don't know" responses were excluded from analyses. Household demographic and health data were extracted from the general questionnaire [47] to characterize households as higher risk [one or more individuals $<5$ yrs, $\geq 65$ yrs, or ever diagnosed with an immunocompromising condition (such as HIV/acquired immunodeficiency syndrome (AIDS), diabetes, cancer)] or not higher risk. Data regarding the respondents' recall of having previously received pet-associated zoonotic disease education (i.e. having ever received information from any source about diseases that can be transmitted from pets or precautions to take with pets) were also extracted from the general questionnaire [47]. For statistical analysis, ordinal levels of each pet husbandry and infection control practice were collapsed to produce dichotomous outcome variables; decisions on how categories were collapsed were made a priori and based on existing recommendations for higher risk households and relevance of comparisons (Table 1) [29-35]. Statistical associations were individually assessed between pet husbandry and infection control practices (outcomes) and 1) households with individuals at higher risk of infections [at least one individual $<5 \mathrm{yrs}, \geq 65 \mathrm{yrs}$, or immunocompromised (exposed) vs. no one fulfilling these criteria (unexposed)] and 2) receipt of zoonotic disease education [previous receipt of pet-associated zoonotic disease education (exposed) vs. no recollection of having received this information (unexposed)]; Table 1. For households with children under 16 yrs of age, statistical associations were individually assessed between child-specific husbandry and infection control practices (e.g., child's involvement and precautions taken in cleaning pet's cages or feces, level of contact with pets) and households with all children at higher risk of infectious disease [presence of all household children $<5$ yrs (exposed) vs. presence of all household children $\geq 5$ yrs (unexposed)]. Due to small sample sizes for many of the variables, associations were measured using univariate exact logistic regression with conditional maximum likelihood estimates (CMLEs). When CMLEs were computed to be infinite, median unbiased estimates were calculated [48]. Odds ratios (ORs) and 95\% confidence intervals (CI) for ORs were used to estimate the strength of associations. Statistical significance was based on a $P$-value $<0.05$.

\section{Results}

Six hundred forty one of the 853 individuals who were approached $(75.1 \%)$ completed the general questionnaire [47]. Of these, 408 respondents (63.7\%) reported having one or more household pets and 401 (98\%) completed the supplemental pet-specific questionnaire. Ownership of dogs, cats, exotic companion animals (such as gerbils and rabbits), reptiles and birds were reported. In addition to having household pets, $16(4.0 \%)$ of the respondents reported they lived on a farm where livestock, horses, or poultry were kept.

\section{Dog-owning households}

Dogs were the most frequently reported owned species, with $68.3 \%$ [(274/401); 95\% CI: 63.5, 72.9] of respondents reporting one or more household dogs. For those respondents listing the number of dogs in the household $(\mathrm{n}=254)$, there was a mean (SD) of $1.3(0.6)$ dogs per household (range: 1-6). The location of the dog was provided by 239 households; 6 households ( $2.5 \%$ ) had 1 or more outdoor only dogs, 231 (96.7\%) had one or more indoor/outdoor dogs, and $2(0.8 \%)$ had both outdoor only and indoor/outdoor dogs.

Household demographics, animal husbandry, attachment and infection control practices for dog-owning households are listed in Table 2. The majority (52\%) of households 
Table 1 Outcomes related to animal husbandry and infection control practices tested for association with presence of higher risk individuals in the household and receipt of zoonotic disease education (Ontario, Canada)

\begin{tabular}{|c|c|}
\hline $\begin{array}{l}\text { Outcome variables (yes/no) tested for association with presence of } \\
\text { of zoonotic disease education }\end{array}$ & higher risk individuals in the household and prior receipt \\
\hline Any uncontrolled outdoor access (cat) ${ }^{2}$ & Dump aquarium water in bathtub, shower, kitchen sink, or bathroom sink (fish) \\
\hline When outdoors, all always in fenced yard or on leash (dog) & Household very attached (cat, dog, reptile, fish, bird, exotic mammal) \\
\hline Within past 3 months, any dogs on a leash at a dog park & Any fed raw animal product (cat, dog) ${ }^{4}$ \\
\hline Within past 3 months, any dogs off leash at a dog park (dog) & Any fed raw animal product not including raw animal treats (dog) \\
\hline All on a flea prevention program (cat, dog) ${ }^{3}$ & Any drink from the toilet (cat, dog) \\
\hline All with outside access on flea prevention program (cat) & Any fed in the kitchen (cat, dog) \\
\hline All on an intestinal parasite prevention program (cat, dog) $)^{3}$ & Any used for breeding (dog) \\
\hline All with outside access on an intestinal parasite prevention program (cat) & Any used for hunting (dog) \\
\hline All have at least annual veterinary examinations (cat, dog) & Any declawed (cat) \\
\hline Any allowed to roam freely through house (reptile) & Any ever bitten anyone (cat, dog) \\
\hline Any allowed to roam in kitchen (reptile) & Any ever scratched anyone (cat) \\
\hline Any cages or animals washed in bathtub or bathroom sink (reptile) & Clean litter boxes daily (cat) \\
\hline
\end{tabular}

Cage or litter boxes cleaned every several days, or more frequently (cat, reptile, bird, exotic mammal)

II. Outcome variables (yes/no) tested for association with all household children being higher risk (less than 5 yrs) and prior receipt of zoonotic disease education ${ }^{1,5}$

\begin{tabular}{ll}
\hline Any children have access to the litter box (cat) & Clean up feces immediately (dog) \\
Any children clean-up feces (cat, dog) & Never sleep in children's bed (cat, dog) \\
Any children wear gloves when cleaning feces $(\mathrm{dog})^{6}$ & Any children play in same area pet goes to the bathroom (dog) \\
Children wash hands after cleaning feces $(\mathrm{dog})^{6}$ & Any children touch pet (cat, dog) \\
Ever lick children's faces (dog) & Children never wash hands after touching pet (cat, dog)
\end{tabular}

${ }^{1}$ Presence of higher risk individuals in the household defined as one or more individuals $<5$ yrs, $\geq 65$ yrs, or ever diagnosed with an immunocompromising condition (e.g., HIV/AIDS, diabetes, cancer). Receipt of zoonotic disease information defined as recollection of having ever received information from any source about diseases that can be transmitted from pets or precautions to take with pets.

${ }^{2}$ Uncontrolled outdoor access defined as households with one or more outdoor only cats or indoor/outdoor cats not placed on a leash when outdoors.

${ }^{3}$ Respondant asked if all dogs/cats on flea or endoparasite prevention programs; the specific components of the programs were not assessed.

${ }^{4}$ Raw animal products defined as raw meat, raw eggs, or raw animal product treats.

${ }^{5}$ Analysis investigating the presence of higher risk children in the household was only performed for children-specific outcomes and only concerned comparison between children-containing households in which all children were $<5$ yrs and those in which all children were $\geq 5$ yrs.

${ }^{6}$ Association only assessed with prior receipt of zoonotic disease education.

surveyed had one or more higher risk individuals. Forty percent of the dog-owning respondents recalled having ever received information about pet-associated zoonotic diseases or precautions to reduce the risk of disease.

Most (76-80\%) dog-owning households had all dogs on flea or endoparasite prevention programs, with $92 \%$ of respondents taking all dogs to a veterinarian at least annually. High risk feeding or drinking habits were observed in many households. Most households (65\%) fed dogs in the kitchen and some (15\%) reported dogs drank from the toilet. High-risk foods were fed to dogs in $28 \%$ of households with raw animal product treats (e.g. pig ears) fed most frequently (22\%), followed by raw meat (4\%), and raw eggs (3\%).

Potential contact between household children ( $<16$ yrs) and fecal material was frequently reported, through their involvement in cleaning up fecal material (24\%) or playing in the same area where the dog tended to defecate $(52 \% ; 58 \%$ of these respondents stated feces were removed weekly or less often). Close contact between dogs and children was often reported, as respondents stated the dog slept in a child's bed (26\%) or licked a child's face (68\%) sometimes or more frequently. Hand washing was reported after children picked up feces (96\%), and sometimes or greater following contact with the $\operatorname{dog}(77 \%)$.

In most cases the presence of higher risk individuals in the household or recalled receipt of zoonotic disease education were not significantly associated with the use of different or additional husbandry or infection control practices compared to other households (Table 3). Households with all children less than 5 yrs of age were less likely to report children cleaned up the dog's feces (OR: 0.05 ; 95\% CI: 0-0.3), but more likely to report a dog ever licked a child's face (OR: 4.1; 1.1-23.5), than households with all children $\geq 5$ yrs. 
Table 2 Demographics, animal husbandry, attachment and practices of dog and cat-owning households (Ontario, Canada)

\begin{tabular}{|c|c|c|c|c|}
\hline \multirow[t]{2}{*}{ Variable } & \multicolumn{2}{|c|}{$\operatorname{Dog}(N=274)$} & \multicolumn{2}{|c|}{ Cat $(\mathrm{N}=191)$} \\
\hline & $\mathrm{N}_{\mathrm{R}}$ & $\mathrm{N}(\%)$ & $\mathrm{N}_{\mathrm{R}}$ & $\mathrm{N}(\%)$ \\
\hline Child under 16 yrs living in household & 274 & $122(44.5)$ & 191 & $78(40.8)$ \\
\hline Child under 5 yrs living in household & 274 & $44(16.1)$ & 191 & $26(13.6)$ \\
\hline All children living in household under 5 yrs & 274 & $25(9.1)$ & 191 & $19(10.0)$ \\
\hline All children living in household 5-16 yrs & 274 & $78(28.5)$ & 191 & $52(27.2)$ \\
\hline Adult $\geq 65$ yrs living in household & 274 & $35(12.8)$ & 191 & $28(14.7)$ \\
\hline Individual living in household ever diagnosed & 227 & $60(26.4)$ & 162 & $55(34.0)$ \\
\hline \multicolumn{5}{|l|}{ with an immunocompromising condition } \\
\hline Individual $<5$ yrs, $\geq 65$ yrs, or ever diagnosed & 237 & $122(51.5)$ & 169 & $90(53.3)$ \\
\hline \multicolumn{5}{|l|}{ with an immunocompromising condition } \\
\hline Previous receipt of pet-associated zoonotic & 255 & $102(40.0)$ & 172 & $75(43.6)$ \\
\hline \multicolumn{5}{|l|}{ disease education ${ }^{1}$} \\
\hline Any ever bitten anyone & 269 & $29(10.8)$ & 184 & $59(32.1)$ \\
\hline Any ever scratched anyone & NA & NA & 180 & $113(62.8)$ \\
\hline Any declawed & NA & NA & 188 & $110(58.5)$ \\
\hline All on flea prevention program² & 263 & $200(76.1)$ & 177 & $98(55.4)$ \\
\hline All on intestinal parasite prevention program ${ }^{3}$ & 258 & $205(79.5)$ & 162 & $68(42.0)$ \\
\hline Any drink from toilet bowl & 267 & $41(15.4)$ & 186 & $36(19.4)$ \\
\hline Any fed in kitchen & 269 & $176(65.4)$ & 189 & $107(56.6)$ \\
\hline Any used for breeding & 268 & $15(5.6)$ & 183 & 0 \\
\hline Any used for hunting & 269 & $3(1.1)$ & NA & NA \\
\hline All visit veterinarian at least annually & 259 & $237(91.5)$ & 184 & $121(65.8)$ \\
\hline Any inappropriately urinate or defecate in & 268 & & 188 & \\
\hline \multicolumn{5}{|l|}{ house $^{4}$} \\
\hline Always & & $1(0.4)$ & & $7(3.7)$ \\
\hline Often & & $14(5.2)$ & & $13(6.9)$ \\
\hline Sometimes & & $74(27.6)$ & & $43(22.9)$ \\
\hline Never & & $179(66.8)$ & & $125(66.5)$ \\
\hline
\end{tabular}

Litter box(es) cleaned

NA

184

Daily

NA

$73(39.7)$

Every several days

Weekly

Every 2 weeks or more

NA

NA

$30(16.3)$

In the past 3 months, have any been

NA

$9(4.9)$

On leash at a dog park

NA

Off leash at a dog park

Doggie daycare or boarding 
Table 2 Demographics, animal husbandry, attachment and practices of dog and cat-owning households (Ontario, Canada) (Continued)

\begin{tabular}{|c|c|c|c|c|}
\hline Sometimes & & $58(21.7)$ & & NA \\
\hline Never & & $14(5.2)$ & & NA \\
\hline Fed to any of the pets & 264 & & 186 & \\
\hline Commercial canned/dry food & & $244(92.4)$ & & $185(99.5)$ \\
\hline Raw eggs & & $9(3.4)$ & & $1(0.5)$ \\
\hline Home cooked pet food & & $15(5.7)$ & & $3(1.6)$ \\
\hline Raw animal product treats & & $59(22.4)$ & & 0 \\
\hline Home cooked human food & & $112(42.4)$ & & $17(9.1)$ \\
\hline Commercial processed pet treats & & $156(59.1)$ & & 70 (37.6) \\
\hline Raw meat & & $11(4.2)$ & & $5(2.7)$ \\
\hline Household's emotional attachment to pet & 268 & & 186 & \\
\hline Very attached & & $247(92.2)$ & & $150(80.7)$ \\
\hline Somewhat attached & & $21(7.8)$ & & $32(17.2)$ \\
\hline Not very attached & & 0 & & $2(1.1)$ \\
\hline Not at all attached & & 0 & & $2(1.1)$ \\
\hline Any children have access to the litter box(es) & NA & NA & 74 & $49(66.2)$ \\
\hline Any children ever clean-up feces ${ }^{5}$ & 119 & $29(24.4)$ & 77 & $19(24.7)$ \\
\hline Wear gloves (or use scooper for dogs) when cleaning up feces & 28 & $24(85.7)$ & 18 & $5(27.8)$ \\
\hline Wash hands after cleaning up feces & 26 & $25(96.2)$ & 19 & $19(100)$ \\
\hline Play in area where the pet goes to the bathroom & 114 & $59(51.8)$ & NA & \\
\hline If play in area, feces removed & 59 & & NA & \\
\hline Immediately & & $12(20.3)$ & & NA \\
\hline Daily & & $13(22.0)$ & & NA \\
\hline Weekly & & $24(40.7)$ & & NA \\
\hline Greater than weekly & & $10(17.0)$ & & NA \\
\hline Any children touch the pet & 118 & $116(98.3)$ & 77 & $72(93.5)$ \\
\hline Children wash hands after touching the pet & 115 & & 70 & \\
\hline Always & & $5(4.4)$ & & $2(2.9)$ \\
\hline Usually & & $31(27.0)$ & & $25(35.7)$ \\
\hline Sometimes & & $53(46.1)$ & & $26(37.1)$ \\
\hline Never & & $26(22.6)$ & & $17(24.3)$ \\
\hline Sleeps in one of the children's beds ${ }^{6}$ & 115 & & 71 & \\
\hline Always & & $9(7.8)$ & & $11(15.5)$ \\
\hline Usually & & $6(5.2)$ & & $10(14.1)$ \\
\hline Sometimes & & $15(13.0)$ & & $21(29.6)$ \\
\hline Never & & $85(73.9)$ & & $29(40.9)$ \\
\hline Licks one of the children's faces ${ }^{7}$ & 115 & & NA & \\
\hline Daily & & $7(6.1)$ & NA & \\
\hline Often & & $21(18.3)$ & & NA \\
\hline Sometimes & & $50(43.5)$ & & NA \\
\hline Never & & $37(32.2)$ & & NA \\
\hline Children's emotional attachment to the pet & 114 & & 77 & \\
\hline Very attached & & $82(71.9)$ & & $52(67.5)$ \\
\hline
\end{tabular}


Table 2 Demographics, animal husbandry, attachment and practices of dog and cat-owning households (Ontario, Canada) (Continued)

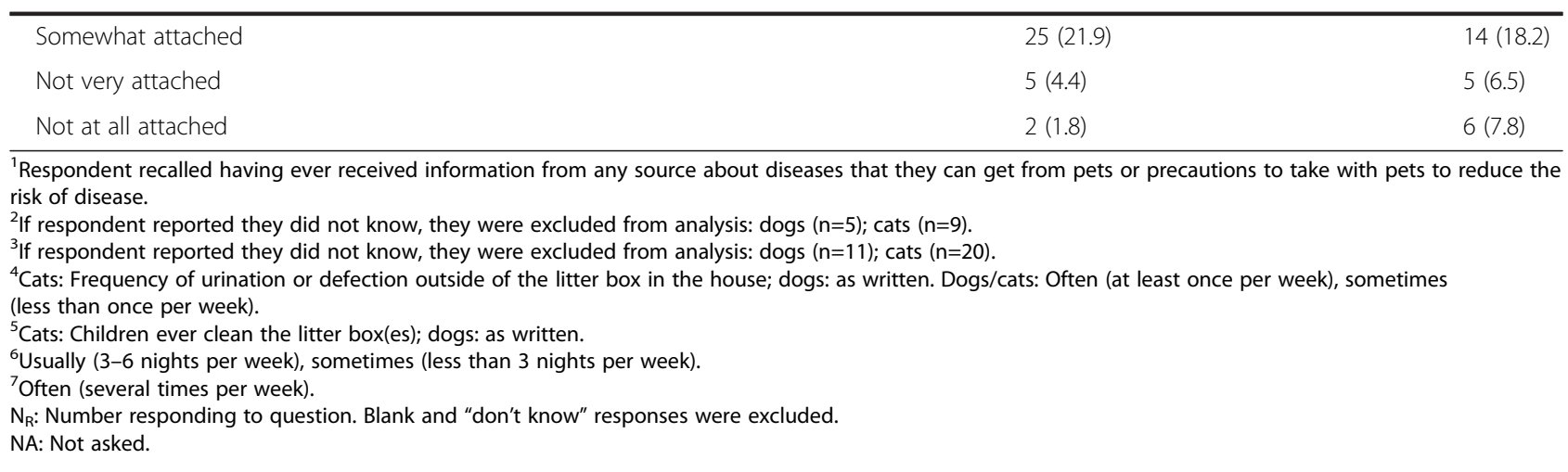

\section{Cat-owning households}

One hundred ninety one respondents (47.6\%; 95\% CI: 42.7, 52.6) reported owning one or more household cats. For those respondents listing the number of cats in the household ( $\mathrm{n}=178)$, there was a mean (SD) of 1.7 (1.4) cats per household (range: 1-11). The location of the cat was provided by 176 households; 7 households (4\%) had one or more outdoor only cats, 114 (65\%) had one or more indoor only cats, and 73 (41\%) had one or more indoor/outdoor cats. However, 41 (56\%) of households with indoor/ outdoor cats kept cats restrained on a leash when outdoors.

Household demographics, animal husbandry, attachment and infection control practices for cat-owning households are listed in Table 2. The majority (53\%) of households had one or more higher risk individuals. Forty-four percent of the cat-owning respondents recalled having ever received information about pet-associated zoonotic diseases or precautions to reduce the risk of disease.

Bites and scratches ever occurring by any of the current household cats were frequently reported (32\% and 63\%, respectively). Approximately half of responding households had all cats on flea (55\%) or endoparasite (42\%) prevention programs, with $66 \%$ of households taking all cats to a veterinarian at least annually. High risk feeding and drinking habits were frequently observed, with many households (57\%) having fed cats in the kitchen. High-risk foods were fed to cats in 3\% of households with raw meat $(3 \%)$ and raw eggs $(0.5 \%)$ reported.

Potential contact between children and fecal material was frequently reported, through their involvement in cleaning up fecal material (25\%) or access to the litter box (66\%). Twenty-one percent of respondents reported the litter box was cleaned weekly or less often; this percentage was similar for households with and without children. Close contact between cats and children was frequently reported, as $59 \%$ of households reported a cat slept in a child's bed. Hand washing was reported after children picked up feces (100\%) and sometimes or greater following contact with the cat $(76 \%)$.
The presence of only children under 5 yrs of age in the household was significantly associated with the occurrence of several infection control practices compared to households with all children 5 yrs of age or older (Table 3). Households with all children less than 5 yrs were less likely to report children cleaned up the cat's feces (OR: 0.07; 95\% CI: 0-0.5), less likely to touch the cat (OR: 0.04; 95\% CI: $0-0.3)$, less likely to have access to the litter box (OR: 0.1 ; 95\% CI: 0.02-0.4), and more likely for the cat to never sleep in the child's bed (OR: 12.9; 95\% CI: 2.4-135.9), than households in which all children were $\geq 5$ yrs.

\section{Fish-owning households}

Fifty-three respondents (13.2\%; 95\% CI: 10.1, 16.9) reported one or more household fish (median 4 fish per household; range: 1-60). Household demographics, animal husbandry, attachment and infection control practices are listed in Table 4. The majority (53\%) of households had one or more higher risk individuals. Thirty percent of the fish-owning respondents recalled having ever received information about pet-associated zoonotic diseases or precautions to reduce the risk of disease.

Forty-four percent of respondents stated they disposed of used aquarium water by pouring it into a location with direct human or food contact [i.e., kitchen sink (24\%), bathroom sink (16\%), bathtub/shower (6\%)]. Those households with higher risk members were less likely to dispose of aquarium water in this manner than households without these members (OR: 0.2; 95\% CI: 0.05-0.9; Table 3). When children were present in a household, they were frequently involved with cleaning the aquarium (30\%) and touching the fish or water (40\%). Over $90 \%$ of households reported that children washed their hands after cleaning, or washed their hands sometimes or greater after touching the fish or water. A large percentage (43-46\%) of households reported the household and children (if present) were not very, or not at all, attached to the fish. 
Table 3 Significant univariable associations between outcomes related to animal husbandry and infection control practices and risk factors reported by pet-owning households (Ontario, Canada)

\begin{tabular}{|c|c|c|c|c|c|c|c|}
\hline Outcome (species) $^{1}$ & $\begin{array}{c}\text { All children }<5 \text { yrs } \\
(\text { Exposed; } N)^{2}\end{array}$ & 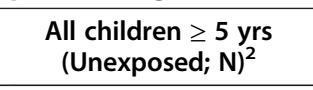 & Risk Exposed & Risk Unexposed & Odds Ratio ${ }^{3}$ & $95 \% \mathrm{Cl}^{3}$ & $P$-value ${ }^{3}$ \\
\hline \multicolumn{8}{|c|}{ Any children have access to the litter boxes (cat) } \\
\hline & 4 & 40 & $25.0 \%$ & $78.4 \%$ & 0.1 & $0.02-0.4$ & 0.0004 \\
\hline \multicolumn{8}{|c|}{ Any children clean up feces (cat) } \\
\hline & 0 & 18 & $0 \%$ & $35.3 \%$ & $0.07^{*}$ & $0-0.5$ & 0.002 \\
\hline \multicolumn{8}{|c|}{ Any children touch pet (cat) } \\
\hline & 13 & 52 & $72.2 \%$ & $100 \%$ & $0.04^{*}$ & $0-0.3$ & 0.001 \\
\hline \multicolumn{8}{|c|}{ Never sleep in children's bed (cat) } \\
\hline & 10 & 14 & $83.3 \%$ & $26.9 \%$ & 12.9 & 2.4-135.9 & 0.001 \\
\hline \multicolumn{8}{|c|}{ Any children clean-up feces (dog) } \\
\hline & 0 & 28 & $0 \%$ & $36.8 \%$ & $0.05^{*}$ & $0-0.3$ & 0.0002 \\
\hline \multicolumn{8}{|c|}{ Ever lick children's face (dog) } \\
\hline & 20 & 45 & $87.0 \%$ & $61.6 \%$ & 4.1 & $1.1-23.5$ & 0.04 \\
\hline Outcome (species) ${ }^{1}$ & $\begin{array}{l}\text { Higher Risk Member } \\
\quad(\text { Exposed; } N)^{4}\end{array}$ & $\begin{array}{l}\text { No Higher Risk Member } \\
(\text { Unexposed; } N)^{4}\end{array}$ & Risk Exposed & Risk Unexposed & Odds Ratio ${ }^{3}$ & $95 \% \mathrm{Cl}^{3}$ & $P$-value ${ }^{3}$ \\
\hline \multicolumn{8}{|c|}{ Within past 3 months, any off leash at a dog park (dog) } \\
\hline & 15 & 29 & $12.3 \%$ & $25.2 \%$ & 0.4 & $0.2-0.9$ & 0.02 \\
\hline \multicolumn{8}{|c|}{ Household very attached (dog) } \\
\hline & 106 & 109 & $88.3 \%$ & $97.3 \%$ & 0.2 & $0.04-0.8$ & 0.01 \\
\hline \multicolumn{8}{|c|}{ Dump aquarium water in bathtub, shower, kitchen sink, or bathroom sink (fish) } \\
\hline & 6 & 12 & $25.0 \%$ & $60.0 \%$ & 0.2 & $0.05-0.9$ & 0.04 \\
\hline \multicolumn{8}{|c|}{ Household very attached (bird) } \\
\hline & 6 & 0 & $54.6 \%$ & $0 \%$ & $11.5^{*}$ & $1.3-\operatorname{lnf}$ & 0.02 \\
\hline
\end{tabular}

${ }^{1}$ Univariable exact logistic regression used to model the likelihood of each husbandry and infection control outcome as a function of selected risk factors (all children < 5 yrs; higher risk member in household). Each row represents a separate regression model.

${ }^{2}$ Performed for children-specific outcomes. Comparison between households with all children $<5$ yrs (exposed) and households with all children $\geq 5$ yrs (unexposed).

${ }^{3}$ Odds ratio, $95 \%$ confidence interval of the odds ratio $(95 \% \mathrm{Cl})$, and $P$-value computed using exact logistic regression.

${ }^{4}$ Comparision between households with $\geq 1$ higher risk members [i.e., $<5$ yrs, $\geq 65$ yrs, ever diagnosed with an immunocompromising condition (exposed)] and households without higher risk members (unexposed).

*Median unbiased estimate computed since odds ratio calculated to be infinite.

\section{Bird-owning households}

Twenty-two respondents (5.5\%; 95\% CI: 3.5, 8.2) reported one or more household birds (median one bird per household; range: 1-40). Household demographics, animal husbandry, attachment and infection control practices for bird-owning households are listed in Table 4. The majority $(57 \%)$ of households had one or more higher risk individuals. Thirty-three percent of the bird-owning respondents recalled having ever received information about pet-associated zoonotic diseases or precautions to reduce the risk of disease. Households with higher risk individuals were more likely to be very attached to the birds than households without these individuals (OR: 11.5; 95\% CI: 1.3-infinite; Table 3).

\section{Exotic companion mammal-owning households}

Twenty-nine respondents (7.2\%; 95\% CI: 4.9, 10.2) reported one or more household exotic mammals (median
1 per household; range: 1-13), consisting of hamsters $(\mathrm{n}=10)$, rabbits (6), guinea pigs (5), rats/mice (4) and hedgehogs, chinchillas and gerbils (2 each). Household demographics, animal husbandry, attachment and infection control practices for exotic mammal-owning households are listed in Table 5. Many (46\%) households had one or more higher risk individuals. Three households (10\%) had at least one child less than 5 yrs of age. Forty-one percent of the respondents recalled having ever received information about pet-associated zoonotic diseases or precautions to reduce the risk of disease.

When children were present in a household, they were frequently involved with cleaning the animal's cage (63\%) or touching the pet $(100 \%)$. Most children reportedly washed their hands after cleaning the cage $(92 \%)$ or washed their hands sometimes or greater after touching the pet (100\%). A minority (42\%) always washed their hands after touching the pet. Most respondents (> 90\%) 
Table 4 Demographics, animal husbandry, attachment and practices of fish and bird-owning households (Ontario, Canada)

Variable
Household Demographics
Child under 16 yrs living in household
Child under 5 yrs living in household
Adult $\geq 65$ yrs living in household
Individual living in household ever diagnosed
with an immunocompromising condition
Individual < 5 yrs, $\geq 65$ yrs, or ever diagnosed
with an immunocompromising condition
Previous receipt of pet-associated zoonotic disease
education ${ }^{1}$
Housing cleaned ${ }^{2}$
Daily
Every several days
Weekly
Every 2 weeks

\begin{tabular}{llll}
\multicolumn{2}{c}{ Fish (N=53) } & \multicolumn{2}{c}{ Bird (N=22) } \\
$\mathbf{N}_{\mathbf{R}}$ & $\mathbf{N}(\%)$ & $\mathbf{N}_{\mathbf{R}}$ & $\mathbf{N}(\%)$ \\
53 & $34(64.2)$ & 22 & $8(36.4)$ \\
53 & $10(18.9)$ & 22 & $1(4.6)$ \\
53 & $2(3.8)$ & 22 & $4(18.2)$ \\
42 & $15(35.7)$ & 20 & $7(35.0)$ \\
45 & & & $12(57.1)$ \\
47 & $24(53.3)$ & 21 & $7(33.3)$ \\
& $14(29.8)$ & 21 & \\
52 & $1(1.9)$ & & $4(19.1)$ \\
& $1(1.9)$ & 21 & $3(14.3)$ \\
& $17(32.7)$ & & $3(14.3)$ \\
& $12(23.1)$ & & $3(14.3)$
\end{tabular}

Greater than every 2 weeks

50

NA

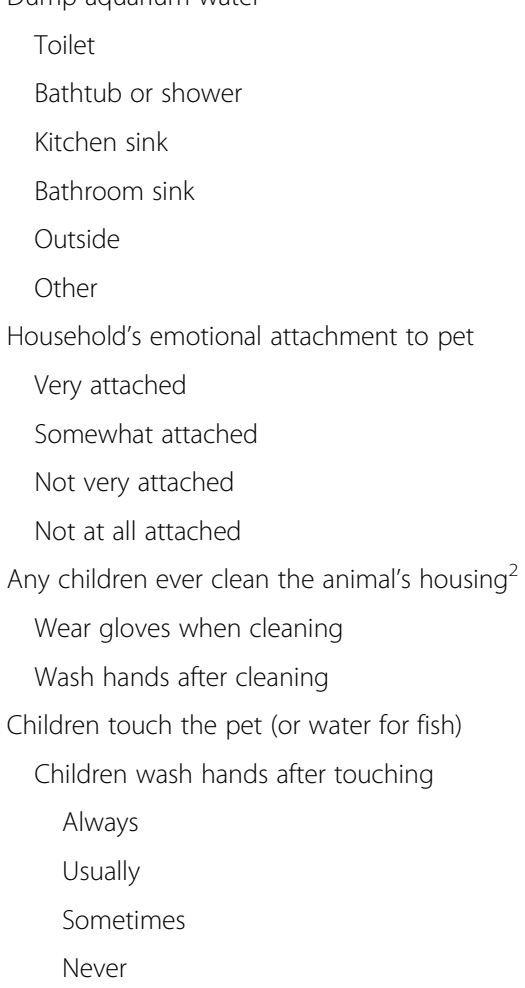

$\begin{array}{ll}20(40.0) & \text { NA } \\ 3(6.0) & N A \\ 12(24.0) & N A \\ 8(16.0) & N A \\ 19(38.0) & N A \\ 3(6.0) & \text { NA }\end{array}$

50

21

\begin{tabular}{|c|c|c|}
\hline $5(10.0)$ & & $6(28.6)$ \\
\hline $22(44.0)$ & & $10(47.6)$ \\
\hline $19(38.0)$ & & $5(23.8)$ \\
\hline $4(8.0)$ & & 0 \\
\hline $10(30.3)$ & 8 & $3(37.5)$ \\
\hline 0 & 3 & $1(33.3)$ \\
\hline $9(90.0)$ & 3 & $2(66.6)$ \\
\hline \multirow[t]{2}{*}{$12(40.0)$} & 8 & $4(50.0)$ \\
\hline & 4 & \\
\hline $4(33.3)$ & & $2(50.0)$ \\
\hline $4(33.3)$ & & $1(25.0)$ \\
\hline $3(25.0)$ & & 0 \\
\hline $1(8.3)$ & & $1(25.0)$ \\
\hline
\end{tabular}

Children's emotional attachment to the pet

30

8

Very attached

$3(10.0)$

$1(12.5)$

$14(46.7)$

$6(75.0)$ 
Table 4 Demographics, animal husbandry, attachment and practices of fish and bird-owning households (Ontario, Canada) (Continued)

\begin{tabular}{|c|c|c|}
\hline Not very attached & $12(40.0)$ & $1(12.5)$ \\
\hline Not at all attached & $1(3.3)$ & 0 \\
\hline
\end{tabular}

reported the household and children (if present) were very or somewhat attached to the pets. No statistically significant associations between husbandry/infection control practices and risk factors were detected.

\section{Reptile-owning households}

Twenty-two respondents (5.5\%; 95\% CI: 3.5, 8.2) reported one or more household reptiles (median one per household; range: $1-11)$, consisting of lizards $(n=9)$, snakes (5), and turtles (9). Household demographics, animal husbandry, attachment and infection control practices for reptileowning households are listed in Table 5. Many households (55\%) had one or more higher risk individuals, with a high proportion (47\%) having been diagnosed with an immunocompromising condition. Two households (9\%) had at least one child less than 5 yrs of age. Forty-one percent of the reptile-owning respondents recalled having ever received information about pet-associated zoonotic diseases or precautions to reduce the risk of disease.

Three respondents (14\%) reported the pet reptile was allowed to roam through the house, kitchen or washed in the kitchen sink. When children were present in a household, they were often involved with cleaning the animal's cage $(40 \%)$ or touching the pet $(78 \%)$. In one household in which children touched the reptile, all children $(n=2)$ were less than 5 yrs. Most respondents reported the children washed their hands after cleaning the cage $(75 \%)$ or washed their hands sometimes or greater after touching the pet (86\%). However, only $57 \%$ always washed their hands after touching the reptile. Many respondents reported the household and children (if present) were not very, or not at all, attached to the reptile (33\% and $40 \%$, respectively). No statistically significant associations between husbandry/infection control practices and risk factors were detected.

\section{Farm-owning households}

Sixteen respondents (4.0\% of those with household pets; $95 \%$ CI: $2.3,6.4)$ reported they lived on a farm. Respondents most commonly listed horses $(n=9)$, chickens (5), cattle and pigs (3 each) as the farm animals present. Fifty percent (7/14) of households for which the data were provided had one or more higher risk individuals. When children were present $[6 / 16(38 \%)]$, they were often involved in higher risk activities. Most [5/6 (83\%)] of such households reported children helped feed and clean-up after the farm animals at least sometimes, and in most households [5/6 (83\%)] children usually or always washed their hands after contact with the animals or their housing.

\section{Discussion}

As pet-human contact frequently occurs and disease transmission is overall rarely reported [47], in most situations such contact should not pose a substantial health risk. However, there are practices that may increase pathogen exposure and individuals $(<5$ yrs, $\geq 65 y r s$, or immunocompromised) for whom these risks are known or presumed to be greater. Reported husbandry and infection control practices in this study indicated opportunities for exposure to pathogens. Respondents reported household children had close contact with pets (e.g., face licking, sleeping in beds, cleaning up pet fecal material). These findings are similar to a previous study in which dogs licked their owners' face (50\%) and dogs and cats slept in an adult's bed (18\%, 30\%, respectively) [37]. The oral cavity of the dog and cat contain numerous potentially zoonotic opportunistic pathogens [49] and face licking can result in transmission of bacteria such as Pasteurella spp. and Capnocytophaga canimorsus [50], potentially resulting in life-threatening disease [22]. For these reasons, some discourage young children and immunocompromised individuals from regularly allowing face licking by pets [50]. The disease risk associated with dogs and cats sleeping in a child's bed is largely unquantified, however sleeping with pets has been identified as a risk factor for several diseases, prompting some to discourage this practice by higher risk individuals [50].

Routine preventive veterinary care and husbandry practices are important techniques for reducing zoonotic disease transmission between pets and people [30,35]. Consistent with previous studies [40,44], most cat- and dog-owning households had these animals examined at least annually by a veterinarian, which allows for identification and education of potential disease concerns and facilitates implementation of an appropriate preventive medicine program. The differences observed between dog and cat preventative veterinary care, with cats having lesser veterinary contact, has been previously noted $[40,44]$. Since cats have less contact with the veterinary 
Table 5 Demographics, animal husbandry, attachment and practices of exotic companion mammal and reptile-owning households (Ontario, Canada)

\begin{tabular}{|c|c|c|c|c|}
\hline \multirow[t]{2}{*}{ Variable } & \multicolumn{2}{|c|}{ Exotic Companion Mammal ${ }^{1}(\mathrm{~N}=29)$} & \multicolumn{2}{|c|}{ Reptile $(\mathrm{N}=22)$} \\
\hline & $\mathrm{N}_{\mathrm{R}}$ & $\mathrm{N}(\%)$ & $\mathrm{N}_{\mathrm{R}}$ & $\mathrm{N}(\%)$ \\
\hline \multicolumn{5}{|l|}{ Household Demographics } \\
\hline Child under 16 yrs living in household & 29 & $19(65.5)$ & 22 & $10(45.5)$ \\
\hline Child under 5 yrs living in household & 29 & $3(10.3)$ & 22 & $2(9.1)$ \\
\hline Adult $\geq 65$ yrs living in household & 29 & $2(6.9)$ & 22 & 0 \\
\hline Individual living in household ever diagnosed & 23 & $8(34.8)$ & 19 & $9(47.4)$ \\
\hline \multicolumn{5}{|l|}{ with an immunocompromising condition } \\
\hline Individual $<5$ yrs, $\geq 65$ yrs, or ever diagnosed & 26 & $12(46.2)$ & 20 & $11(55.0)$ \\
\hline \multicolumn{5}{|l|}{ with an immunocompromising condition } \\
\hline Previous receipt of pet-associated zoonotic & 27 & $11(40.7)$ & 17 & $7(41.2)$ \\
\hline \multicolumn{5}{|l|}{ disease education ${ }^{2}$} \\
\hline \multicolumn{5}{|l|}{ Animal Husbandry, Attachment and Practices } \\
\hline Cage cleaned & 29 & & 21 & \\
\hline Daily & & $2(6.9)$ & & $1(4.8)$ \\
\hline Every several days & & $6(20.7)$ & & $3(14.3)$ \\
\hline Weekly & & $18(62.1)$ & & $6(28.6)$ \\
\hline Every 2 weeks & & $3(10.3)$ & & $5(23.8)$ \\
\hline Greater than every 2 weeks & & 0 & & $6(28.6)$ \\
\hline Animals allowed to roam through house & NA & NA & 22 & $2(9.1)$ \\
\hline Animals allowed to roam in kitchen & NA & NA & 22 & $2(9.1)$ \\
\hline Animals/cages washed in kitchen sink & NA & NA & 22 & $3(13.6)$ \\
\hline Animals/cages washed in bathtub or bathroom & NA & NA & 18 & $5(27.8)$ \\
\hline \multicolumn{5}{|l|}{ sink } \\
\hline Household's emotional attachment to pet & 29 & & 21 & \\
\hline Very attached & & $16(55.2)$ & & $3(14.3)$ \\
\hline Somewhat attached & & $11(37.9)$ & & $11(52.4)$ \\
\hline Not very attached & & $2(6.9)$ & & $4(19.1)$ \\
\hline Not at all attached & & 0 & & $3(14.3)$ \\
\hline
\end{tabular}

Questions answered by households with one or more children under 16 yrs

Any children ever clean the animal's cage

Wear gloves when cleaning

$1(8.3)$

Wash hands after cleaning

$11(91.7)$

Animals roam in children's room

Children touch the pet

Children wash hands after touching

Always
Usually
Sometimes
Never


Table 5 Demographics, animal husbandry, attachment and practices of exotic companion mammal and reptile-owning households (Ontario, Canada) (Continued)

Not very attached
Not at all attached
${ }^{1}$ Exotic companion mammals included rabbits, hedgehogs, and rodents (such as gerbils, hamsters, guinea pigs, chinchillas, mice, and rats).
${ }^{2}$ Respondent recalled having ever received information from any source about diseases that they can get from pets or precautions to take with pets to reduce the
risk of disease.
$\mathrm{N}_{\mathrm{R}}$ : Number responding to question. Blank and "don't know" responses were excluded.
NA: Not asked.

healthcare system yet have close interactions with household members, educational approaches that reach beyond the veterinary clinic may be required.

Concerning husbandry practices were observed in all owned species. Feeding of raw meat or egg products are well-established risk factors for salmonellosis in dogs $[45,51]$ and presumably cats. Raw animal product treats (i.e. pig ears) have historically been a concern for Salmonella infections in pets and pet-owners, with outbreaks identified $[52,53]$. Although feeding these items is discouraged, particularly in higher risk households [54], many households reported this practice. These risks are further compounded by feeding pets in the kitchen (frequently reported in this study) as documented in an outbreak investigation of salmonellosis in infants linked to Salmonella-contaminated pet food [55]. As several outbreaks of human salmonellosis have been associated with contaminated dry commercial pet food [55,56], feeding pets in the kitchen should be discouraged, especially in higher risk households [29]. Concerning husbandry practices were frequently reported in reptile-owning homes (e.g., infrequent hand washing, permitting them to roam freely through a home or kitchen). Due to the high prevalence of Salmonella shedding by healthy reptiles [57] and the high incidence of human salmonellosis attributed to reptile contact [24], the reported practices are strongly discouraged $[34,58]$.

Hand hygiene serves a critical role in reducing the risk of zoonotic infections. Our results were similar to previous studies in which $96 \%$ of dog owners reported they usually or greater washed their hands after picking up feces [36] and 15\% always washed their hands after touching the dog [37]. For lower risk circumstances, such as contact with a dog or cat, the level of hand hygiene documented in our study is likely adequate; however, in higher-risk situations, such as following contact with a reptile, hand washing should always occur.

Across all animal species that were owned, many households had an individual at higher risk of infections ( $<5$ yrs, $\geq 65$ yrs, immunocompromised). Although pet ownership has previously been commonly reported in households with individuals who are immunocompromised $[15,38,39]$ and of extremes of age [40-43], it was concerning to observe this trend with higher risk species such as reptiles, which are discouraged from being kept in higher risk households [29,31-34,58]. However, this finding was not surprising as a previous study involving this respondent group found households with higher risk individuals did not differ from the remaining households regarding their knowledge or perceived risk of pet-associated disease or recall of having received information regarding pet-associated disease risks [47]. Physicians and veterinarians are in an important position to offer guidance on proper pet selection. In order to tailor recommendations, physicians should obtain a history of contact with pets or other animals as part of every wellness evaluation, especially for individuals at higher risk of zoonotic disease, and veterinarians should utilize methods to encourage clients to divulge health information relevant to disease risk status for household members.

Despite evaluating over 50 practices consistent with existing recommendations for individuals at greater risk for infectious disease [29-35], few significant associations were identified. Most of those identified suggested a lower risk of practice occurrence in households with young children; the extent to which such decisions were purposefully implemented versus simply a consequence of young age is unknown. The finding that young children were at increased risk to be licked on the face by the household dog was expected due to their age and size, but nonetheless concerning because of reports of lickassociated infections in children [22,50].

The limited use of husbandry and infection control practices by households with higher risk individuals was disappointing but not surprising. Previous research on this respondent group found pet owners were overall unconcerned about pet-associated zoonoses and a minority (36\%) recalled previously receiving zoonotic disease education [47]. Most respondents were comfortable with their level of knowledge of, and methods to reduce, zoonotic disease risk [47]. While it is unclear whether participants had reasonable knowledge of those areas, their perceived competency could reduce the impetus to seek out further information.

General zoonotic disease counselling was previously associated with statistically higher zoonotic disease knowledge scores in this respondent group [47], yet no such difference was observed in husbandry or infection control practices in the present study. This discrepancy may have arisen due to the minimally defined nature of 
this variable (i.e. timing and quality of information provided were not assessed), but it is also possible that although education imparted improved knowledge of zoonotic disease risks, due to a lack of concern for pet-associated zoonoses or competing time commitments, infection control and husbandry practices were unaffected. It is also possible that education regarding diseases was not accompanied by adequate information about preventive measures.

This study identified numerous pet husbandry and infection control practices that may increase disease risk in pet-owning households. In order to determine the relative importance of these practices and educational efforts that should be employed, targeted observational studies are needed. While guidelines for infection-control practices in higher risk households are available, it appears that individuals in such households are no better educated on the topic of pet-associated zoonoses [47], nor do their husbandry or infection control practices differ from other households. Educational efforts are needed for households with individuals at higher risk of infections. Given the multifaceted nature of this topic, with communication barriers among physicians, veterinarians and the public [59-61], all members of the family healthcare team (i.e., physicians, veterinarians, public health) must work together to reach the common goal of reducing the public's pet-associated disease risks.

Several biases may have been introduced into this study and affected the results. We acquired our data from a convenience sample from the waiting room of general practice physician offices from a limited geographic area. All Canadian residents receive medically necessary healthcare services at no charge [62], reducing the potential that variable access to physicians would result in a biased study population. As previously discussed [47], based on census data, our sample appeared to be representative of the region. Response bias cannot be excluded, however as blank and "don't know" responses were uncommon $(<20 \%$ for each question with the majority $<10 \%$ ), the magnitude of this bias is likely limited. As many questions addressed health-related actions taken by respondents for which they may have known what answers were ideal, respondents may have misclassified household practices. In these cases, information provided would suggest better husbandry and infection control practices than actually existed. This was perhaps most likely for questions surrounding hand washing [63]. As only a single individual from each household participated in the study, it is possible reported observations and perceptions may not have been representative of the household. Due to the nature of this study, small sample sizes were often encountered, which in some cases prohibited analysis and in others may have limited statistical power. Furthermore, small sample sizes prohibited multivariable analysis and the ability to investigate confounding. A large number of individual regression analyses were conducted and corrections were not made for this multiplicity of testing; estimates are likely to have an increased type I error and fewer significant associations may exist than reported.

\section{Conclusions}

This study characterized pet husbandry and infection control practices that relate to zoonotic disease risks in pet-owning households in Ontario, Canada, and identified deficiencies that could result in exposure to pathogens and human zoonotic infections. Individuals at higher risk of infections were frequently present in pet-owning households, regardless of species. With few exceptions, households with members at higher risk for infectious disease and those who recalled having received education on pet-associated disease risks followed similar practices to households without these individuals or education. Targeted educational efforts are indicated for households with individuals at higher risk of infections and those with high-risk species (e.g., reptiles). Healthcare team members, including veterinarians, physicians and public health practitioners, have the potential to serve as valuable resources in reducing pet-associated disease risks, however all must jointly work to address this area and devote more attention toward the public's interaction with animals. Further research is needed to determine the reasoning behind household infection control and husbandry practices and the respective roles of education and perceptions in shaping these practices.

\section{Additional file}

Additional file 1: Supplemental questionnaire for households with pets.

Competing interests

The authors declare they have no competing interests.

\section{Authors' contributions}

All authors participated in the study concept, design and questionnaire development. JWS enrolled participating clinics and administered questionnaires to participating patients. JWS was responsible for data analysis, data interpretation and manuscript preparation. All authors provided input on data analysis, interpretation and final manuscript development. All authors have approved the final version of the manuscript.

\section{Acknowledgements}

The authors thank staff and students at the University of Guelph (Departments of Population Medicine and Pathobiology), McMaster University (Department of Pediatrics) and the Children's Hospital of Eastern Ontario (Division of Infectious Diseases) for their input into the questionnaire. They also thank the two medical practices and their patients for their participation. JMS was supported through a Canadian Institutes of Health Research (CIHR) Institute of Population and Public Health/ Public Health Agency of Canada Applied Public Health Research Chair. 


\section{Author details}

${ }^{1}$ Department of Pathobiology, Ontario Veterinary College, University of Guelph, Guelph, Ontario N1G2W1, Canada. ${ }^{2}$ Centre for Public Health and Zoonoses, University of Guelph, Guelph, Ontario N1G2W1, Canada. ${ }^{3}$ Department of Population Medicine, Ontario Veterinary College, University of Guelph, Guelph, Ontario N1G2W1, Canada. ${ }^{4}$ Current address: Department of Veterinary Preventive Medicine, The Ohio State University, College of Veterinary Medicine, 1920 Coffey Rd., Columbus, OH 43210, USA.

\section{Received: 23 January 2013 Accepted: 23 May 2013}

Published: 29 May 2013

\section{References}

1. Butler JR, Bingham J: Demography and dog-human relationships of the dog population in Zimbabwean communal lands. Vet Rec 2000, 147(16):442-446.

2. Baldock FC, Alexander L, More SJ: Estimated and predicted changes in the cat population of Australian households from 1979 to 2005. Aust Vet $J$ 2003, 81(5):289-292.

3. Downes M, Canty MJ, More SJ: Demography of the pet dog and cat population on the island of Ireland and human factors influencing pet ownership. Prev Vet Med 2009, 92(1-2):140-149.

4. Slater MR, Di Nardo A, Pediconi O, Villa PD, Candeloro L, Alessandrini B, De Papa S: Cat and dog ownership and management patterns in central Italy. Prev Vet Med 2008, 85(3-4):267-294.

5. Murray JK, Browne WJ, Roberts MA, Whitmarsh A, Gruffydd-Jones TJ: Number and ownership profiles of cats and dogs in the UK. Vet Rec 2010, 166(6):163-168.

6. Perrin T: The Business Of Urban Animals Survey: the facts and statistics on companion animals in Canada. Can Vet J 2009, 50(1):48-52.

7. Alves MC, Matos MR, Reichmann ML, Dominguez MH: Estimation of the dog and cat population in the State of Sao Paulo. Rev Saude Publica 2005, 39(6):891-897.

8. American Veterinary Medical Association: U.S. pet ownership \& demographics sourcebook. Schaumburg (Illinois): American Veterinary Medical Association; 2007.

9. Friedmann E, Son H: The human-companion animal bond: how humans benefit. Vet Clin N Am: Small Anim Pract 2009, 39(2):293-326.

10. Reaser JK, Clark EE, Meyers NM: All creatures great and minute: a public policy primer for companion animal zoonoses. Zoonoses Public Health 2008, 55(8-10):385-401.

11. Poresky RH, Hendrix C: Differential effects of pet presence and pet-bonding on young children. Psychol Rep 1990, 67(1):51-54.

12. Melson GF, Schwarz RL, Beck AM: Importance of companion animals in children's lives-implications for veterinary practice. J Am Vet Med AssoC 1997, 211(12):1512-1518.

13. Carmack BJ: The role of companion animals for persons with AIDS/HIV. Holist Nurs Pract 1991, 5(2):24-31.

14. Castelli P, Hart LA, Zasloff RL: Companion cats and the social support systems of men with AIDS. Psychol Rep 2001, 89(1):177-187.

15. Conti L, Lieb S, Liberti T, Wiley-Bayless M, Hepburn K, Diaz T: Pet ownership among persons with AIDS in three Florida counties. Am J Public Health 1995, 85(11):1559-1561.

16. Raina P, Waltner-Toews D, Bonnett B, Woodward C, Abernathy T: Influence of companion animals on the physical and psychological health of older people: an analysis of a one-year longitudinal study. J Am Geriatr SoC 1999, 47(3):323-329.

17. Hale CR, Scallan E, Cronquist AB, Dunn J, Smith K, Robinson T, Lathrop S, Tobin-D'Angelo M, Clogher P: Estimates of enteric illness attributable to contact with animals and their environments in the United States. Clin Infect Dis 2012, 54(Suppl 5):S472-S479.

18. Weese JS, Fulford MB: Companion Animal Zoonoses. lowa: Wiley-Blackwell 2011:3-298.

19. Friedman CR, Hoekstra RM, Samuel M, Marcus R, Bender J, Shiferaw B, Reddy S, Ahuja SD, Helfrick DL, Hardnett F, Carter M, Anderson B, Tauxe RV Emerging Infections Program FoodNet Working Group: Risk factors for sporadic Campylobacter infection in the United States: a case-control study in FoodNet sites. Clin Infect Dis 2004, 38(Suppl 3):S285-S296.

20. Tenkate TD, Stafford RJ: Risk factors for Campylobacter infection in infants and young children: a matched case-control study. Epidemiol Infect 2001, 127(3):399-404
21. Younus M, Wilkins MJ, Davies HD, Rahbar MH, Funk J, Nguyen C, Siddiqi AE, Cho S, Saeed AM: The role of exposures to animals and other risk factors in sporadic, non-typhoidal Salmonella infections in Michigan children. Zoonoses Public Health 2010, 57(7-8):e170-e176.

22. Kobayaa H, Souki RR, Trust S, Domachowske JB: Pasteurella multocida meningitis in newborns after incidental animal exposure. Pediatr Infect Dis J 2009, 28(10):928-929.

23. De Boer MG, Lambregts PC, Van Dam AP, Van T, Wout JW: Meningitis caused by Capnocytophaga canimorsus: when to expect the unexpected. Clin Neurol Neurosurg 2007, 109(5):393-398.

24. Mermin J, Hutwagner L, Vugia D, Shallow S, Daily P, Bender J, Koehler J, Marcus R, Angulo FJ: Emerging Infections Program FoodNet Working Group: Reptiles, amphibians, and human Salmonella infection: a population-based, case-control study. Clin Infect Dis 2004, 38(Suppl 3):S253-S261.

25. Lin $A E$, Davies JE: Occurrence of highly fluoroquinolone-resistant and methicillin-resistant Staphylococcus aureus in domestic animals. Can J Microbiol 2007, 53(7):925-929.

26. Platell JL, Trott DJ, Johnson JR, Heisig P, Heisig A, Clabots CR, Johnston B, Cobbold RN: Prominence of an 075 clonal group (clonal complex 14) among non-ST131 fluoroquinolone-resistant Escherichia coli causing extraintestinal infections in humans and dogs in Australia. Antimicrob Agents Chemother 2012, 56(7):3898-3904.

27. Mani I, Maguire JH: Small animal zoonoses and immunocompromised pet owners. Top Companion Anim Med 2009, 24(4):164-174

28. Abbas AK, Lichtman AH, Pillai S: Congenital and acquired immunodeficiencies. In Cellular and molecular immunology. 6th edition. Philadelphia: Saunders; 2007:463-488.

29. Angulo FJ, Glaser CA, Juranek DD, Lappin MR, Regnery RL: Caring for pets of immunocompromised persons. Can Vet J 1995, 36(4):217-222

30. Glaser CA, Powers EL, Greene CE: Zoonotic infections of medical importance in immunocompromised humans. In Infectious diseases of the dog and cat. 4th edition. Edited by Greene CE. St. Louis: Elsevier; 2012:1141-1162

31. Centers for Disease Control and Prevention: Guidelines for preventing opportunistic infections among hematopoietic stem cell transplant recipients: recommendations from $C D C$, Infectious Disease Society of America, American Society of Blood and Marrow Transplantation. MMWR Recomm Rep 2000, 49(RR-10):1-125. CE1-7.

32. Centers for Disease Control and Prevention: Guidelines for the Prevention and Treatment of Opportunistic Infections among HIV-exposed and HIV-infected children: recommendations from CDC, the National Institutes of Health, the HIV Medicine Association of the Infectious Diseases Society of America, the Pediatric Infectious Diseases Society, and the American Academy of Pediatrics. MMWR Recomm Rep 2009, 58(RR-11):1-166.

33. Pickering LK, Marano N, Bocchini JA, Angulo FJ: Committee on Infectious Diseases: Exposure to nontraditional pets at home and to animals in public settings: risks to children. Pediatrics 2008, 122(4):876-886.

34. Centers for Disease Control and Prevention: Compendium of Measures to Prevent Disease Associated with Animals in Public Settings, 2011. MMWR 2011, 60(RR-4):1-24

35. Lappin MR: Pet ownership by immunocompromised people. Compend Contin Educ Pract Vet 2002, 24(5A):16-25.

36. Westgarth C, Pinchbeck GL, Bradshaw JW, Dawson S, Gaskell RM, Christley RM: Dog-human and dog-dog interactions of 260 dog-owning households in a community in Cheshire. Vet Rec 2008, 162(14):436-442.

37. Overgaauw PA, Van Zutphen L, Hoek D, Yaya FO, Roelfsema J, Pinelli $E_{\text {, }}$ Van Knapen F, Kortbeek LM: Zoonotic parasites in fecal samples and fur from dogs and cats in The Netherlands. Vet Parasitol 2009, 163(1-2):115-122

38. Siegel JM, Angulo FJ, Detels R, Wesch J, Mullen A: AIDS diagnosis and depression in the Multicenter AIDS Cohort Study: the ameliorating impact of pet ownership. AIDS Care 1999, 11(2):157-170.

39. Abarca VK, Del Lopez PJ, Pena DA, Lopez GJC: Pet ownership and health status of pets from immunocompromised children, with emphasis in zoonotic diseases. Rev Chilena Infectol 2011, 28(3):205-210.

40. Leslie BE, Meek AH, Kawash GF, McKeown DB: An epidemiological investigation of pet ownership in Ontario. Can Vet J 1994 35(4):218-222 
41. Westgarth C, Pinchbeck GL, Bradshaw JW, Dawson S, Gaskell RM, Christley RM: Factors associated with dog ownership and contact with dogs in a UK community. BMC Vet Res 2007, 3:5.

42. Westgarth C, Heron J, Ness AR, Bundred P, Gaskell RM, Coyne KP, German AJ, McCune S, Dawson S: Family pet ownership during childhood: findings from a UK birth cohort and implications for public health research. Int J Environ Res Public Health 2010, 7(10):3704-3729.

43. Ramon ME, Slater MR, Ward MP: Companion animal knowledge, attachment and pet cat care and their associations with household demographics for residents of a rural Texas town. Prev Vet Med 2010, 94 (3-4):251-263.

44. Volk JO, Felsted KE, Thomas JG, Siren CW: Executive summary of the Bayer veterinary care usage study. J Am Vet Med Assoc 2011, 238(10):1275-1282.

45. Leonard EK, Pearl DL, Finley RL, Janecko N, Peregrine AS, Reid-Smith RJ, Weese JS: Evaluation of pet-related management factors and the risk of Salmonella spp. carriage in pet dogs from volunteer households in Ontario (2005-2006). Zoonoses Public Health 2011, 58(2):140-149

46. Waterloo, Ontario. 2006. Community Profiles http://www12.statcan.ca/ census-recensement/2006/dp-pd/prof/92-591/index.cfm?Lang=E.

47. Stull JW, Peregrine AS, Sargeant JM, Weese JS: Household knowledge, attitudes and practices related to pet contact and associated zoonoses in Ontario. Canada. BMC Public Health 2012, 12(1):553.

48. Mehta CR, Patel NR: Exact logistic regression: theory and examples. Statist Med 1995, 14(19):2143-2160.

49. Forsblom B, Sarkiala-Kessel E, Kanervo A, Vaisanen ML, Helander M, Jousimies-Somer H: Characterisation of aerobic gram-negative bacteria from subgingival sites of dogs-potential bite wound pathogens. J Med Microbiol 2002, 51(3):207-220.

50. Chomel BB, Sun B: Zoonoses in the bedroom. Emerg Infect Dis 2011, 17(2):167-172.

51. Kukanich KS: Update on Salmonella spp. contamination of pet food, treats, and nutritional products and safe feeding recommendations. J Am Vet Med Assoc 2011, 238(11):1430-1434.

52. Clark C, Cunningham J, Ahmed R, Woodward D, Fonseca K, Isaacs S, Ellis A, Anand C, Ziebell K, Muckle A, Sockett P, Rodgers F: Characterization of Salmonella associated with pig ear dog treats in Canada. J Clin Microbiol 2001, 39(11):3962-3968.

53. Centers for Disease Control and Prevention (CDC): Human salmonellosis associated with animal-derived pet treats-United States and Canada, 2005. MMWR Morb Mortal Wkly Rep 2006, 55(25):702-705.

54. Finley R, Reid-Smith R, Ribble C, Popa M, Vandermeer M, Aramini J: The occurrence and anti-microbial susceptibility of Salmonellae isolated from commercially available pig ear pet treats. Zoonoses Public Health 2008, 55(8-10):455-461.

55. Behravesh CB, Ferraro A, Deasy M, Dato V, Moll M, Sandt C, Rea NK, Rickert R, Marriott C, Warren K, Urdaneta V, Salehi E, Villamil E, Ayers T, Hoekstra RM, Austin JL, Ostroff S, Williams IT: Salmonella Schwarzengrund Outbreak Investigation Team: Human Salmonella infections linked to contaminated dry dog and cat food, 2006-2008. Pediatrics 2010, 126(3):477-483.

56. Centers for Disease Control and Prevention (CDC): Notes from the field: human Salmonella infantis infections linked to dry dog food - United States and Canada, 2012. MMWR Morb Mortal Wkly Rep 2012:61-436.

57. Hydeskov HB, Guardabassi L, Aalbaek B, Olsen KE, Nielsen SS, Bertelsen MF: Salmonella prevalence among reptiles in a zoo education setting. Zoonoses Public Health 2013, 60(4):291-5.

58. Centers for Disease Control and Prevention (CDC): Reptile-associated salmonellosis-selected states, 1998-2002. MMWR Morb Mortal Wkly Rep 2003, 52(49):1206-1209.

59. Grant S, Olsen CW: Preventing zoonotic diseases in immunocompromised persons: the role of physicians and veterinarians. Emerg Infect Dis 1999, 5(1):159-163.

60. Von Matthiessen PW, Sansone RA, Meier BP, Gaither GA, Shrader J: Zoonotic diseases and at-risk patients: a survey of veterinarians and physicians. AIDS 2003, 17(9):1404-1406.

61. Hill WA, Petty GC, Erwin PC, Souza MJ: A survey of Tennessee veterinarian and physician attitudes, knowledge, and practices regarding zoonoses prevention among animal owners with HIV infection or AIDS. J Am Vet Med Assoc 2012, 240(12):1432-1440.
62. Health Canada: Canada Health Act Annual Report 2009-2010. Ottawa, Ontario; 2010. 978-1-100-16312-3:4

63. Moret L, Tequi B, Lombrail P: Should self-assessment methods be used to measure compliance with handwashing recommendations? A study carried out in a French university hospital. Am J Infect Control 2004, 32(7):384-390.

doi:10.1186/1471-2458-13-520

Cite this article as: Stull et al:: Pet husbandry and infection control practices related to zoonotic disease risks in Ontario, Canada. BMC Public Health 2013 13:520.

\section{Submit your next manuscript to BioMed Central and take full advantage of:}

- Convenient online submission

- Thorough peer review

- No space constraints or color figure charges

- Immediate publication on acceptance

- Inclusion in PubMed, CAS, Scopus and Google Scholar

- Research which is freely available for redistribution 